\title{
LAND USE/LAND COVER CHANGES USING MULTI-TEMPORAL SATELLITE
}

\author{
H.T.T. Nguyen ${ }^{1 *}$, Q.T.N. Chau ${ }^{1}$, A.T. Pham ${ }^{2}$, H.T. Phan ${ }^{1}$, P.T.X. Tran ${ }^{1}$, H.T. Cao ${ }^{1}$, T.Q. Le ${ }^{3}$, D.T.H. Nguyen ${ }^{4}$ \\ ${ }^{1}$ Dept. of Forest Resource and Environment management, Tay Nguyen University - huongthanh.frem@ttn.edu.vn; \\ quynhchau0709@gmail.com; phanhang84@gmail.com; phantran8883@gmail.com; caohoai.tnu@gmail.com \\ ${ }^{2}$ Department of Agriculture and Rural Development Dak Nong - phamtuanhln@gmail.com \\ ${ }^{3}$ Space Technology Institute - lequantoan82@gmail.com \\ ${ }^{4}$ Land Resources Department, College of Environment and Natural Resources, Can Tho University - nthdiep@ctu.edu.vn
}

\section{Commission IV} KEYWORDS: Landsat images, land use/land cover change (LULCC), accuracy assessment, forest cover changes, Random Forest
algorithm

\begin{abstract}
:
Producing the map of land use land cover change (LULCC) at the local extent is fundamental for a variety of applications such as vegetation, forest covers, soil degradation, and global warming. Understanding the directions and spread trend of LULCC plays significant role in obtaining useful data for the local authorities in making land-use policies under the context of climate change. Dak Nong is located in the Central Highlands of Vietnam having the largest tropical forest. Over the past decades, the natural forest in the region has significantly declined due to the pressure of population growth and social-economic development. The current study analyzed the LULCC in the province over the four periods: 2005-2018, 2005-2010, 2010-2015, and 2015-2018. Information from Landsat satellite imagery captured in 2005, 2010, 2015, and 2018 was utilized to create the LULC maps and detect the land-use changes. The Random Forest (RF) was employed to categorize the images into nine different LULC classes. The study showed that classification accuracy was achieved from $72.49 \%$ to $84.55 \%$ with a kappa coefficient of 0.69 to 0.81 . The findings revealed a significant decrease in the natural forest over time from $53.1 \%$ to $42.7 \%, 36.8 \%$, and $34.6 \%$ in $2005,2010,2015$, and 2018 , respectively. Meanwhile, the other types of LULC showed an increase in the area over the periods, especially croplands. It was noticeable that the continuous decrease in the forest area over the years has put pressure on the natural environmental resources and generated the risk of climate change.
\end{abstract}

\section{INTRODUCTION}

One of the worldwide natural challenges associated with the change of the surface of Earth is the dynamics of LULC (Mustard et al., 2004; Daniels et al., 2007; Prakasam, 2010).

LULCC identification is basic for a deep understanding of landscape dynamics during a known period. LULCC may be a popular and advanced process primarily driven by humans and natural circumstances, which have led to changes that would affect the features of the physical environment (Ruiz-Luna et al., 2003; Turner, Ruscher, 2004). Although several sources exist that bring about global environmental changes, LULCC related to human activities has been considered as the main source contributing to this process with exceptional rates, magnitudes, and spatial extents (Turner et al., 1994). The conversion of tropical forest areas to other lands including large-scale agricultural land is concerned as one of the most vital components of LULC (Myers et al., 2000), and the main contribution of LULCC in tropical regions is agricultural expansion (Lambin et al., 2001). It is recognized that land conversion has threatened the loss of forest covers and ecological functions (Haines-Young, 2009; Khoi, Murayama, 2010). The information about LULC and the conceivable outcomes for its ideal utilize is basic for the determination, outline, and application of land-use strategies following sustainable management of natural resources coping with climate change. Based on this informative data, the changes ịn LULC is driven by population growth will be managed (Rawat, Kumar, 2015).
Remotely sensed data have been demonstrated to be a useful method for identifying LULCC in recent decades. Together with the information from satellite imagery, the analysis performed using GIS techniques to determine driving forces of changes has been used as a basis for policymakers to design different areas of the development structure of society such as land allocation for the agriculture, urban and industrial areas (Selcuk et al., 2003).

Being one of the provinces located in the Central Highlands, Dak Nong has a high diversity of natural forest resources in the country with various types of tropical forests due to environmental and climatic factors represented by natural and physical features of the region (Thai, 1978). There has not only been a high level of forest degradation but also land-use transformation in the province. These activities have had devastating influences by transferring woodlands into other landuse types such as the transition from natural forests to annual and perennial crops or conversion of forested areas to hydroelectricity development or rubber plantation. As a result, a decrease in natural forest covers is becoming increasingly in the study area. Hence, it is necessary to analyze LULC changes based on satellite imagery to generate an accessible database used for the long-term management of natural resources.

\section{MATERIALS AND METHODS}

\subsection{Study Area}

The research was implemented in Dak Nong province situated in the Central Highlands, Vietnam. Its mean elevation ranges from 600 to $700 \mathrm{~m}$ above sea level. The area is characterized as the

\footnotetext{
${ }^{*}$ Corresponding author
} 
subtropical monsoon climate dividing this region into two different seasons (the rainy season and the dry season). The mean rainfall is $2,500 \mathrm{~mm}$ (the rainy season represents more than 90 percent of the rainfall all year round). The study area extends over $6,516 \mathrm{~km}^{2}$, including various types of LULC with substantial fragmentation.

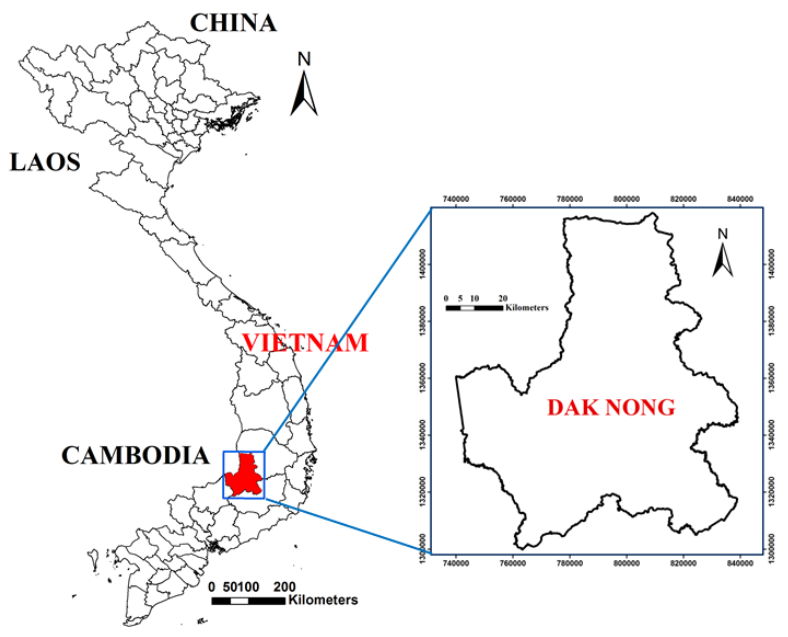

Figure 1. The location of the study area

\subsection{Data Sources}

2.2.1 Data Acquisition: Data sets from the Landsat 5 and Landsat 8 SR (Surface Reflectance Tier 1) were used in the research. The images were collected and processed through Google Earth Engine (GEE). Landsat 5 and Landsat 8 SR atmospherically corrected surface reflectance from the sensors of Landsat 5 ETM and Landsat 8 OLI/TIRS, respectively. Landsat 5 SR data contain three visible bands (B1, B2, B3): one nearinfrared (VNIR: B4) and two short-wave infrared (SWIR: B5, B7) bands, handed to orthorectified surface reflectance; and one thermal infrared (TIR: B6) band prepared to orthorectified brightness temperature. The VNIR and SWIR bands have a-30m per pixel resolution. A resampling process of the TIR band was initially chosen at $-120 \mathrm{~m} /$ pixel resolution. Landsat 8 SR scenes contain four visible bands (B1, B2, B3, B4): ortho-rectifications of surface directional reflectance was applied to one near-infrared (VNIR: B5) and two short-wave infrared (SWIR: B6, B7) bands, while two thermal infrared (TIR: B10, B11) bands were processed to brightness temperature ortho-rectifications (Google Developers: Earth Engine Data Catalog). Landsat 5 SR data was corrected using LEDAPS (Department of the Interior U.S. Geological Survey. 2019a); LaSRC (Department of the Interior U.S. Geological Survey, 2019b) was used to correct Landsat 8 SR, and both included a mask for clouding and shadowing, through CFMASK (Foga et al., 2017), as well as a saturation mask per-pixel.

As four periods were considered in this study, including 2005, 2010, 2014, and 2018, Landsat 5 and 8 SR data were used to ensure that the entire area was covered and the effects of clouds were eliminated. Accordingly, the Landsat image data sets were divided into four temporal periods including i) a collection of Landsat 5 SR scenes in 2004 and 2005; ii) a collection of Landsat 5 SR scenes in 2009 and 2010; iii) a collection of Landsat 8 SR scenes in 2014 and 2015, and iv) a collection of Landsat 8 SR scenes in 2017 and 2018.

The distinctive seasonal images defined for individual periods were achieved to analyze the LULC changes regarding the median collected values. Integration of seasonal image data with the normalized difference vegetation index (NDVI) (Pettorelli et al., 2011) to improve the classified results that have been suggested in previous studies (Yacouba, 2009; Manandhar, 2009). The multi-spectral bands of Landsat 5 SR included Blue (B1), Green (B2), Red (B3), NIR (B4), SWIR 1 (B5), TIR (B6); SWIR 2 (B7), and NDVI and the multi-spectral bands of Landsat 8 SR of Ultral Blue (B1), Blue (B2), Green (B3), Red (B4), NIR (B5), SWIR 1 (B6), SWIR 2 (B7), TIR 1 (B10), TIR 2 (B11) and NDVI were employed in the study. Information on images is described in Table 1 below.

\begin{tabular}{ccccc}
\hline $\begin{array}{c}\text { Type of } \\
\text { Landsat } \\
\text { data }\end{array}$ & $\begin{array}{c}\text { Respective } \\
\text { Year }\end{array}$ & $\begin{array}{c}\text { Acquisition } \\
\text { Date }\end{array}$ & $\begin{array}{c}\text { Number } \\
\text { of images } \\
\text { involved }\end{array}$ & $\begin{array}{c}\text { Number } \\
\text { of bands }\end{array}$ \\
\hline $\begin{array}{c}\text { Landsat 5 } \\
\text { SR Tier 1 }\end{array}$ & $2004-2005$ & $\begin{array}{c}01 / 01 / 2005- \\
31 / 12 / 2006\end{array}$ & 97 & 08 \\
\hline $\begin{array}{c}\text { Landsat 5 } \\
\text { SR Tier 1 }\end{array}$ & $2009-2010$ & $\begin{array}{c}01 / 01 / 2009- \\
12 / 31 / 2010\end{array}$ & 84 & 08 \\
\hline $\begin{array}{c}\text { Landsat 8 } \\
\text { SR Tier 1 }\end{array}$ & $2014-2015$ & $\begin{array}{c}01 / 01 / 2014- \\
12 / 31 / 2015\end{array}$ & 143 & 10 \\
\hline $\begin{array}{l}01 / 01 / 2017- \\
12 / 31 / 2018\end{array}$ & 128 & 10 \\
\hline SR Tier 1 & $2017-2018$ & $\begin{array}{c}0 \\
\text { Table 1. Information on Landsat satellite imagery used in the } \\
\text { classification }\end{array}$
\end{tabular}

The JavaScript API Code Editor in the GEE was employed as a tool for collecting images to quantify the changes of LULC types. Pre-processing of Landsat satellite data was done to lower the spatial distribution impacts of topographical and bidirectional reflectance. Besides the cloud zones in the image were masked out, and then removal of shadows was undertaken during the process. A combination of the median function was added to produce a single image implying the median value of all images in the filter tool. The post-pre-processing images were then resampled to a certain spatial scale and subsetted according to the boundary of the study area. The whole pre-processing was conducted through the GEE (Gorelick et. al, 2017).

2.2.2 Training and Validation Data: There has studied on the combination of field data collection using very fine spatial resolution imagery data from Google Earth based on Landsat images for classification and other reliable sources such as maps and available data information (Sothe et al., 2017; Teluguntla et al., 2018). The authors have obtained good results and demonstrated the objectivity of the sampling process.

The random samples for training and validation in the current work were examined based on: i) different points from the field; ii) fine resolution and very high-resolution images from Google Earth and iii) the existing Dak Nong Forest Inventory/LULC Maps. Furthermore, the sample areas were also collected directly by the current Landsat satellite image whereby the samples can be clearly distinguished from others based on our prior experience. It is possible to collect, define, and interpret sample areas that can be easily identified using fine resolution and very fine resolution image data accessible from Google Earth. This provides access to the entire study area, and it is also an effective process due to the low cost and less time-consuming that is usually widely used in RS and GIS studies (Kennedy et al, 2015; Teluguntla et al., 2018). However, it is difficult to distinguish some categories from LULC such as semi-evergreen forest, plantation forest, and some perennial industrial crops in the region. Therefore, field data collection should be acquired to maintain information data entry for training and validation.

\subsection{Methods}


2.3.1 Imagery Classification: The RF algorithm proposed by Breiman (2001) was employed to classify Landsat images. Optimal values of the algorithm such as mtry, ntree, and variable importance were selected as illustrated by Nguyen et al. (2018, 2020). The higher number of ntree is, the more stable result for variable importance can be produced. There are two indicators including Mean Decrease Accuracy (MDA) and Mean Decrease Gini (MDG) used for estimating the accurate model. Of which, MDA is the accuracy associated with each predictor variable based on the out-of-bag error rate (OOB). While Gini impurity is a measure of how often a randomly chosen element from the set would be incorrectly labeled if it is randomly labeled according to the distribution of labels in the subset. For this study, MDA values were applied to determine the importance of variables. According to Nguyen et al., (2018) revealed that ntree ranging from 1 to 500; equivalent to 300 produced the best result.

Within the study area, nine separable LULC categories were distinguished on LS images: (1) Evergreen broadleaved forest; (2) Semi-evergreen forest (the forest that consists of a mixture of evergreen and deciduous dipterocarp tree species); (3) Dipterocarp deciduous forest; (4) Plantation forest; (5) Mature rubber ( $\geq 3$ years old); (6) Cropland; (7) Residential area; (8) Water surface; and (9); and other types of land (including grassland, shrubs, bare land, unplanned land, abandoned land, and so on).

2.3.2 Accuracy Assessment: Assessing classified images is a necessary step before the final classification result is being accepted (Nguyen, 2011). Accuracy assessment was calculated by creating a confusion matrix between ground truth and classified pixels. The classification results were evaluated through overall accuracy (OA), kappa coefficient $(\mathrm{K})$, producer accuracy (PA), and user accuracy (UA). The confusion matrix is the error between the pixels has been categorized and the real pixel, the error matrix is the analytical results. It is believed that determining the driving factors of differences in the confusion matrix may be the most significant and useful steps in the LULC mapping from remotely detected information (Congalton, Green, 1999).
Classification accuracy assessment was implemented using the method of randomly dividing the sample data set into two independent parts, with $60 \%$ of the data used for the classification and the remaining $40 \%$ of the sample employed to assess the accuracy of the classified images.

2.3.3 Detection of Land Use/Land Cover Changes: In remote sensing, identification of land use changes depicts the process of defining and monitoring the dynamics in LULC types over distinctive periods. It has been evident that LULC change analysis can offer quantitative results of the spatial distribution in a certain area (Tewolde, Cabral, 2011; Ahmed, Ahmed, 2012).

The analysis of LULCC was implemented based on the Landsat data archived from multi-temporal periods to analyze the land use types and the changing trend in utilizing the ArcGIS software. The identified changes were transformations within the nine LULC categories. This allowed us quantifying the modification that occurs from time 1 to time 2, and it also helps us understand the increase and decrease between land use covers, the conversion in the area as well as contribution between LULC classes (Eastman, 2016; Balogun, Ishola, 2017). The format of these data should be similar and simultaneously. It is noticeable that all data have to be projected together with coordinate projection (Nguyen, Ngo, 2018).

\section{RESULTS AND DISCUSSIONS}

\subsection{LULC Classification and Accuracy Assessment}

Table 2 presents the results of the OA, coefficient index, PA, and UA. The results showed that over the four temporal periods, OA ranged from $72.49 \%$ to $84.55 \%$, and Kappa from 0.69 to 0.81 indicated a substantial agreement between the classification results and reference data. The highest accuracy (OA) of $84.55 \%$ and Kappa index of 0.81 were achieved from the LULC map in 2015. Whereas, the classified image in 2005 produced the lowest OA of $72.49 \%$ and a coefficient $\mathrm{K}=0.69$. However, there was an insignificant difference between 2010 and 2018. The accuracy of 2005 was the lowest (OA by $72.49 \%$; K by 0.69 ), however, the difference between 2010 and 2018 was insignificant.

\begin{tabular}{|c|c|c|c|c|c|c|c|c|c|c|c|c|}
\hline YEAR & $\mathrm{OA}$ & $\mathrm{K}$ & $\mathrm{Cl}$. & 1 & 2 & 3 & 4 & 5 & 6 & 7 & 8 & 9 \\
\hline \multirow{2}{*}{2005} & \multirow{2}{*}{72.49} & \multirow{2}{*}{0.69} & PA & 82.53 & 72.43 & 67.08 & 78.21 & 80.95 & 84.92 & 79.59 & 87.82 & 44.68 \\
\hline & & & UA & 84.96 & 72.86 & 64.1 & 85.53 & 52.75 & 74.66 & 63.47 & 94.6 & 51.51 \\
\hline \multirow{2}{*}{2010} & \multirow{2}{*}{77.35} & \multirow{2}{*}{0.75} & PA & 89.88 & 74.42 & 72.34 & 74.21 & 83.41 & 67.55 & 82.09 & 99.02 & 71.27 \\
\hline & & & UA & 76.21 & 75.25 & 76.16 & 81.81 & 84.67 & 67.11 & 83.91 & 91.29 & 71.76 \\
\hline \multirow{2}{*}{2015} & \multirow{2}{*}{84.55} & \multirow{2}{*}{0.81} & PA & 84.88 & 89.73 & 86.54 & 88.34 & 100.0 & 77.6 & 91.98 & 83.84 & 57.99 \\
\hline & & & UA & 85.27 & 86.56 & 82.47 & 89.44 & 100.0 & 79.25 & 86.62 & 83.84 & 80.99 \\
\hline \multirow{2}{*}{2018} & \multirow{2}{*}{78.28} & \multirow{2}{*}{0.75} & PA & 87.79 & 46.35 & 42.09 & 81.76 & 81.99 & 66.77 & 86.03 & 100.0 & 68.07 \\
\hline & & & UA & 90.2 & 50.72 & 47.53 & 79.39 & 68.65 & 66.77 & 79.86 & 100.0 & 70.0 \\
\hline
\end{tabular}

Where Class 1: Evergreen; 2: Semi-Evergreen; 3: Dipterocarp; 4: Plantation; 5: Rubber; 6: Cropland; 7: Residential; 8: Water Surface; 9: Other types of land.

Table 2. Overall Accuracy (\%), Kappa coefficient, Producer's Accuracy (\%), and User's Accuracy (\%) index for the classification images of the three time-periods

A study used the Landsat TM images of a watershed (basin) for classifying land covers: agriculture, population, and the Rocky Mountains, and the study achieved the highest accuracy of $74 \%$ (Al-Ahmadi, Hames, 2009). It can be easily seen that Landsat images are useful for LULC classification with regards to accuracy in general. Islam et al., (2018) revealed the OA of over $80 \%$ for all cases when using Landsat time-series images including Landsat TM and Landsat OLI to classify these images. However, the classification accuracy of classification depends not only on the type of satellite imagery used but also on other factors, for which the classification method is also one of the important factors (Heydari, et al., 2018).

The PA and UA among LULC categories in each result were different. The PA and UA of the classes gained more than $65 \%$ in most of the cases excepting for LULC classified from 2005 and 2018, such as semi-evergreen, dipterocarp, rubber, residential, and other types of land. Comparing to others, the water surface is a very distinctive feature in the satellite image due to its low reflectance, so the classification accuracy is always 
very high (even at $100 \%)$. This study was no exception with the $\mathrm{PA}$ and UA reaching from 83 to $100 \%$ in all cases.

The natural evergreen forest was less likely to be confused with other land covers with PA and UA greater than $82 \%$ (except 2010 with UA $76 \%$ ). This is due to different characteristics of this forest type from other vegetation covers regarding species, age ranges, and canopy diversity, which are typical features of tropical forests (Nguyen et al., 2020).

The classification error of the dipterocarp deciduous forest was higher than in other types of forest. Particularly, the UA and PA exhibited less than $50 \%$ in 2018. The dipterocarp deciduous forest dominated by trees that shed leaves seasonally. However, not all species lose their leaves simultaneously and there also have several species belonging to evergreen or semi-evergreen forests mixed-growing with deciduous tree species. Therefore, the dipterocarp forest is easy to get confused with other lands such as bare land, annual crops, etc. in the dry season but the semi-evergreen forest in the rainy season (Nguyen et al., 2020).

The semi-evergreen is a transitional forest between evergreen and dipterocarp deciduous forest, which in reality cannot be uniformly distributed in terms of ratio and density between deciduous and non-deciduous species. It is suggested that human disturbance is one of the factors resulting in such distribution. Hence, the semi-evergreen forest is often confused with the evergreen and dipterocarp forests.
The accuracy of plantation forests was also relatively high, with PA and UA above $70 \%$ in all periods. However, there were confusions with evergreen forests and industrial crops. Most of the plantation forests consist of only one or several species of the even-aged trees, which looks like industrial cropland. Moreover, some plantation forests are developed in gaps and exploited areas of natural forests, which can affect the degree of distinction between planted forests and natural evergreen forests.

\subsection{Land Use/Land Cover Changes}

The LULC maps of the classified images of the four study periods $(2005,2010,2015,2018)$ are presented in Figure 2. The maps show that the natural forests are scattered in districts and significantly reduced from 2005 to 2018 . The current natural forests are strongly divided; most of the natural forests remain only in protected areas such as national parks, nature reserves, and protected forests.

Table 3 indicates that cropland has been continuously increased over the years $(2005,2010,2015,2018)$ from $31 \%$ to $45 \%, 52 \%$, and $53 \%$, respectively. Conversely, the second land cover was the evergreen forest, which however shows a decrease over the years from $42 \%$ to $34 \%, 29 \%$, and $27 \%$.

\begin{tabular}{|c|c|c|c|c|c|c|c|c|}
\hline \multirow[b]{2}{*}{ LULC } & \multicolumn{2}{|l|}{2005} & \multicolumn{2}{|l|}{2010} & \multicolumn{2}{|c|}{2015} & \multicolumn{2}{|c|}{2018} \\
\hline & ha & $\%$ & ha & $\%$ & ha & $\%$ & ha & $\%$ \\
\hline EverGreen & $277,988.76$ & 42.63 & $221,708.61$ & 34.00 & $189,227.34$ & 29.02 & $178,062.03$ & 27.30 \\
\hline Semi-EverGreen & $27,887.67$ & 4.28 & $17,856.90$ & 2.74 & $22,467.87$ & 3.45 & $23,781.87$ & 3.65 \\
\hline Dipterocarp & $35,283.87$ & 5.41 & $32,057.28$ & 4.92 & $21,374.82$ & 3.28 & $16,035.66$ & 2.46 \\
\hline Plantation & $5,480.82$ & 0.84 & $6,533.28$ & 1.00 & $6,974.46$ & 1.07 & $8,037.00$ & 1.23 \\
\hline Rubber & $1,247.04$ & 0.19 & $3,601.08$ & 0.55 & $18,740.07$ & 2.87 & $22,750.47$ & 3.49 \\
\hline Crop Land & $204,580.17$ & 31.37 & $295,557.39$ & 45.32 & $341,390.25$ & 52.35 & $349,699.50$ & 53.62 \\
\hline Residential & $4,373.55$ & 0.67 & $4,478.22$ & 0.69 & $6,163.83$ & 0.95 & $6,319.89$ & 0.97 \\
\hline Water Surface & $2,464.92$ & 0.38 & $2,897.19$ & 0.44 & $9,244.71$ & 1.42 & $10,332.09$ & 1.58 \\
\hline Others & $92,856.24$ & 14.24 & $67,473.09$ & 10.35 & $36,579.69$ & 5.61 & $37,144.53$ & 5.70 \\
\hline Total & $652,163.04$ & 100.00 & $652,163.04$ & 100.00 & $652,163.04$ & 100.00 & $652,163.04$ & 100.00 \\
\hline
\end{tabular}

Table 3. Area of LULC categories over years (ha) 


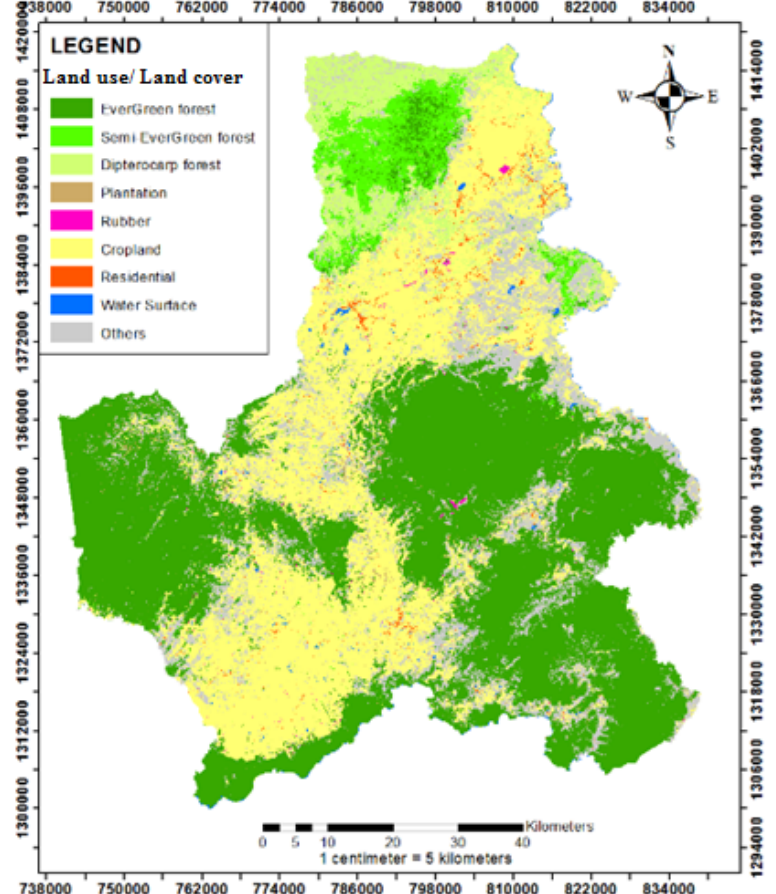

a)

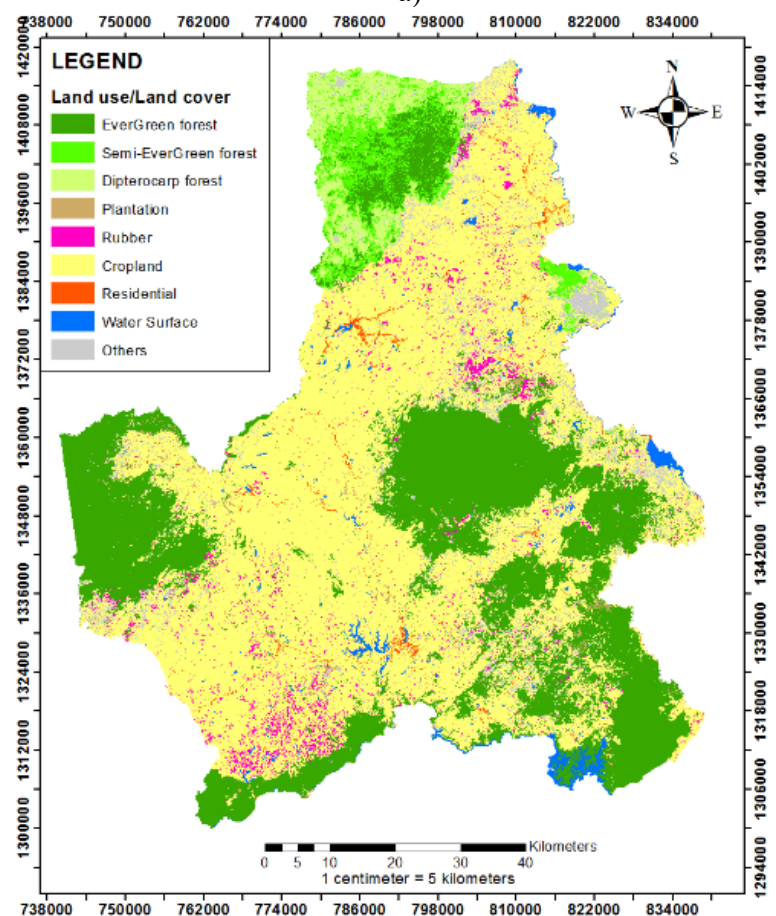

c)

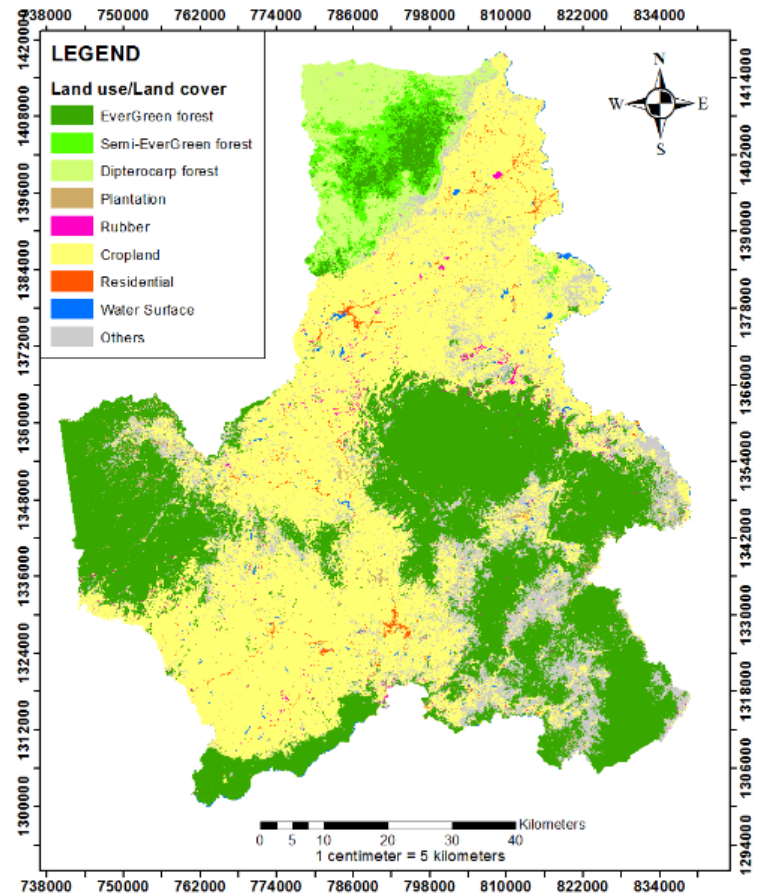

b)

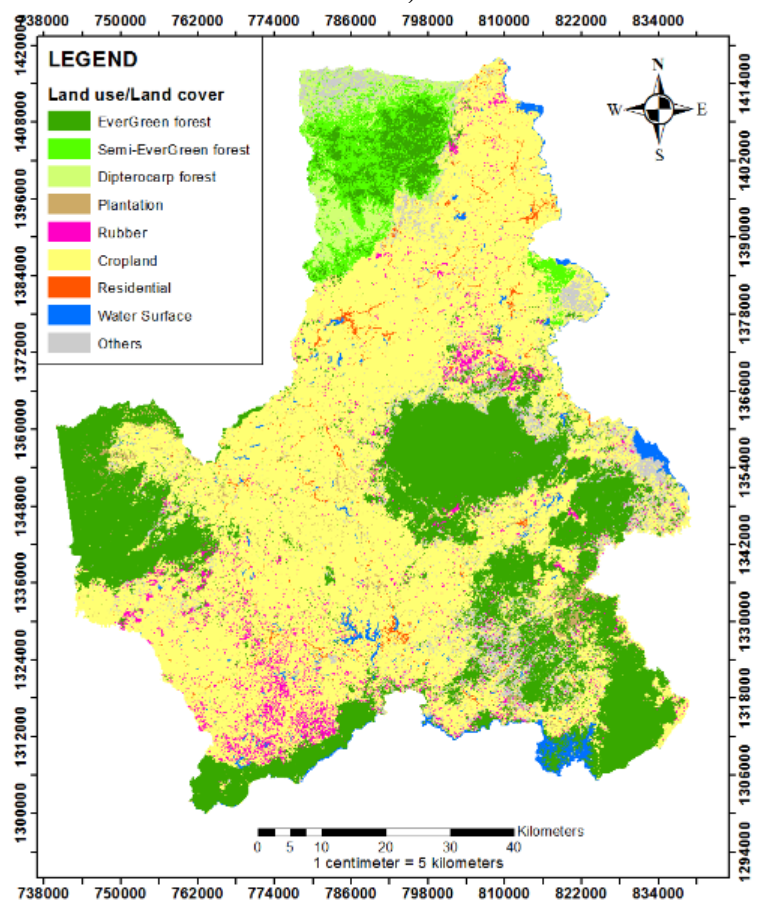

d)

Figure 2. LULC maps obtained from image classification of the four time-periods: a) 2005, b) 2010, c) 2015 and d) 2018

Based on the classified images over the years (2005-2010-20152018), the changes of the LULC area are summarized in Figure 3. In general, for forest classes, the area of natural evergreen forest and dipterocarp forest decreased over the years. In contrast, the area of semi-evergreen and planted forests gradually increased over periods. For non-forest cover categories, the area of crop-land cover, residential cover, and water surface cover increased over the years due to economic, hydropower, social development, and population growth, while other types of land were volatile but the trend declined over periods.
Between 2005 and 2018, natural forests decreased by almost 120,000 hectares, of which 100,000 hectares of evergreen forest was lost. Similarly, semi-evergreen forest and dipterocarp forests were also reduced by more than 10,000 and 3,000 hectares, respectively. By contrast, cropland showed a significant increase of 140,000 hectares, followed by rubber with about 20,000 hectares compared to other types of LULC. 


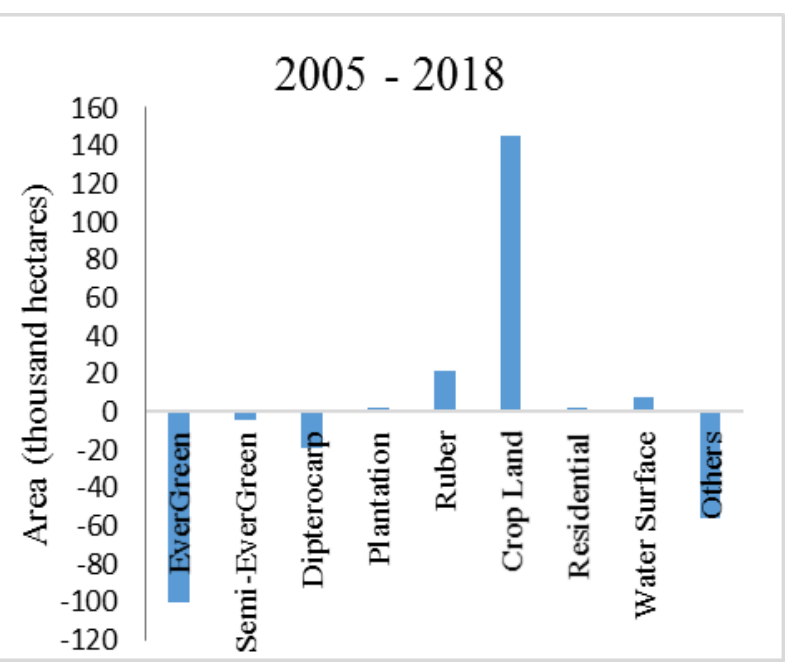

Figure 3. LULCC in period 2005-2018

The main driver of deforestation and forest degradation in Vietnam is the encroachment of lands in various forms associated with the expansion of commercial trees and infrastructure. Also, the price of industrial trees increases to put pressure on acquiring and using the land for the production of coffee, rubber (and other crops). The forest transformation on a small scale, gradual and illegal conversion of the forests for local crop production is accelerating forest degradation (World Bank, 2019). Dak Nong province is no exception, corresponding to the decrease in natural forest area, most of the other LU/LC types are increasing, especially agricultural and industrial land covers. This shows that the expansion of agricultural and industrial crops has led to a rapid reduction in natural forest areas in Dak Nong province.

\subsection{Forest Covers Change Analysis}

Based on the statistical results for the area over the years, we analyzed the changes in the forest cover rate from 2005 to 2018. In which, the forest cover included natural forest and plantation forest and the non-forest covers consisted of the remaining other covers. The analysis results are shown in Figure 4.

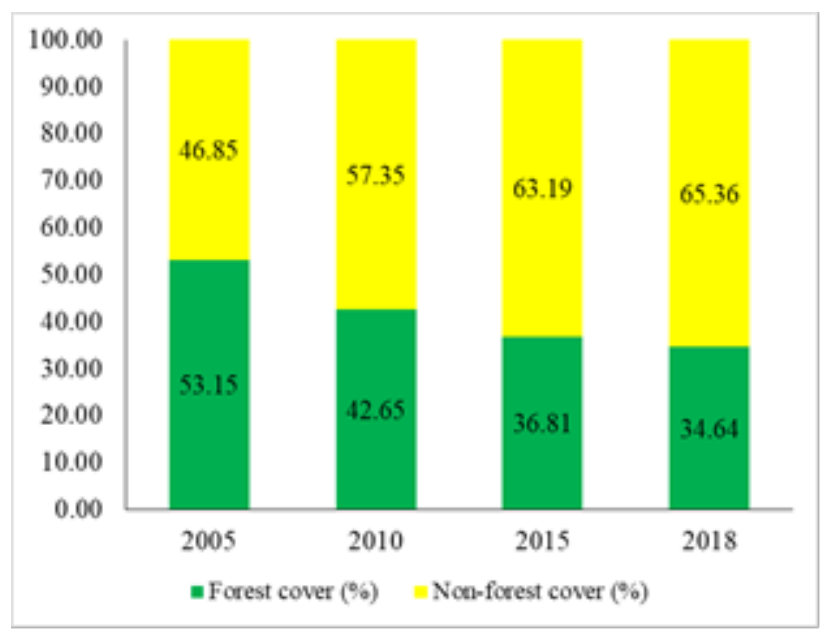

Figure 4. Changes in forest cover over time-period

Figure 4 indicates that over the period from 2005 to 2018, the region experienced a significant decrease in forest cover, while non-forest covers showed an upward trend of area. In particular, the percentage of forest cover in 2005 was $53,15 \%$, with that figure for the year 2018 obtained by 34\% which reduced approximately one third compared to 2005 . This was the time following the establishment of Dak Nong province and the beginning of the socio-economic development process. The analysis periods had an unequal number of years, so an annual forest change rate was calculated to compare between periods (Table 4).

Within 13 years, the area of natural forest decreased by $36,14 \%$ compared to the initial forest area (2005), and the annual decrease rate of $2,78 \%$. While the plantation forest area increases insignificantly by $3,59 \%$ in comparison with the area in 2005 . Of the three main types of natural forest, the dipterocarp forest had the most loss of $54,55 \%$, followed by evergreen forest at $35,95 \%$ and semi-evergreen forest at $14,72 \%$. The annual lost forest rate shows a sharp decrease in a natural forest in the 20052018 period with $4,08 \%$ per year. From $2010-2015$, the average annual natural forest area lost $2,84 \%$ of the total area. The yearly lost forest rate in the $2015-2018$ period is lower than that in the previous years.

\begin{tabular}{lrrrrrrrr}
\hline & \multicolumn{2}{r}{$2005-2010$} & \multicolumn{2}{c}{$2010-2015$} & \multicolumn{2}{r}{$2015-2018$} & \multicolumn{2}{r}{$2005-2018$} \\
\cline { 2 - 8 } Forest cover & Period & Yearly & Period & Yearly & Period & Yearly & Period & Yearly \\
\hline Natural forest & -20.38 & -4.08 & -14.19 & -2.84 & -6.52 & -2.17 & -36.14 & -2.78 \\
EverGreen & -20.25 & -4.05 & -14.65 & -2.93 & -5.90 & -1.97 & -35.95 & -2.77 \\
Semi-EverGreen & -35.97 & -7.19 & 25.82 & 5.16 & 5.85 & 1.95 & -14.72 & -1.13 \\
Dipterocarp & -9.14 & -1.83 & -33.32 & -6.66 & -24.98 & -8.33 & -54.55 & -4.20 \\
Plantation & 19.20 & 3.84 & 6.75 & 1.35 & 15.23 & 5.08 & 46.64 & 3.59 \\
\hline
\end{tabular}

Table 4 . The percentage (\%) of area change of forest cover types

The obtained results show that Dak Nong province has witnessed a considerable decrease in forested covers for thirteen years. There are some of many reasons causing the forest loss in the area. The population grew rapidly both planted and spontaneous immigration since after the reforms began to take effect in 1990 . Between the census of 1999 and 2009 the Central Highlands including Dak Nong province experienced the highest demographic growth rates in the country (Central Population and Housing Census Steering Committee, 2010). The Central Highlands is a subtropical monsoon climate that creates a high diversity of landscape with favourable conditions for planting industrial crops including coffee, pepper, cocoa, and mulberry. Accordingly, natural conditions have attracted many groups of people who mainly come from the northern parts and central provinces migrating to this region for settling down (Rambo et al., 1995). They destroyed natural forests for agriculture of which the largest driver of deforestation was due to planting commercial crops such as coffee, pepper, cassava (MARD, 2019). Because of starvation and population growth, the northern minorities who free migrated to the Central Highlands have illegally encroached the forested lands for their cultivation. Once they settle down the property, it means forested lands cleared to make way for their 
farms. Therefore, conflicts that trigger between local authorities and migrants are unavoidable since there are many unclear decisions approved during the process of land-use right certificate (Salemink, 2018). In essence, the negative impact of migration often associates with deforestation and disagreement on lands which traditionally used by the indigenous people. Furthermore, most of the forest land areas have been converted into croplands or farmlands increasingly causing damages to natural forests by immigrants. Additionally, priority for economic and social development have also dramatically affected the loss of natural forest area. As other provinces located in the Central Highland, a considerable areas of the natural forest Dak Nong province has been destroyed for hydropower construction, transportation, and converted to rubber areas (MARD, 2019).

\section{CONCLUSIONS}

Nine different LULC classes were discriminated throughout the study area using Landsat 5, 8 satellite imagery data in 2009, 2015, and 2018, four of which were forest cover categories. The results achieved accuracy from $72.49 \%$ to $84.55 \%$. In general, over the revised years, there was a trend of a significant reduction in the natural forest, while the remaining classes showed an increase. The continued decline in the forest area over the years has caused pressures on the natural environment and contributed to the risk of local and global climate change.

\section{ACKNOWLEDGEMENTS}

This work is a part of the research project within the PEER program (Partnerships for Enhanced Engagement in Research), sponsored by USAID and the research project CNVT/ VTUD.06/18-20 hosted by the Institute of Space Technology, VAST. The authors would like to thank the sponsors and all of the people involved in the field data collection for classification and validation.

\section{REFERENCES}

Ahmed, B., Ahmed, R., 2012: Modeling urban land cover growth dynamics using multi-temporal satellite images: A case study of Dhaka, Bangladesh. ISPRS Int. J. Geo-Inf., 1, 3-31.

Al-Ahmadi, F.S., Hames, A. S., 2009: Comparison of Four Classification Methods to Extract Land Use and Land Cover from Raw Satellite Images for Some Remote Arid Areas, Kingdom of Saudi Arabia. JKAU Earth Sciences, 20(1), 167191.

Balogun, I. A., Ishola, K. A., 2017: Projection of Future Changes in Landuse/Landcover using Multi-Layer Perceptron Markov Model Over Akure City, Nigeria. Glo J. of Sci Fron Re: H. Env \& Earth Sci, 17 (1), 30-44.

Breiman, L., 2001: Random forests. Machine Learning, 45, 532.

Congalton, R.G., Green, K., 2019: Assessing the accuracy of remotely sensed data: Principles and Practices ( $3^{\text {rd }}$ edition). Boca Raton FL 33486-2742. CRC press

Central Population and Housing Census Steering Committee, 2010. The 2009 Vietnam population and housing census: major findings. Hanoi: Central Population and Housing Census Steering Committee.

Daniels, A.E., Painter, K., Southworth, J., 2008: Milpa imprint on the tropical dry forest landscape in Yucatan, Mexico: Remote sensing \& field measurement of edge vegetation, Agric. Ecosyst, 123(4), 293-304.

Department of the Interior U.S. Geological Survey, 2019a. Landsat 4-7 surface reflectance (LEDAPS) product guide. LSDS-1370. Version 2.0 (accessed on 15 July 2019).

Department of the Interior U.S. Geological Survey, 2019b. Landsat 8 surface reflectance code (LASRC) product guide. LSDS-1368. Version 2.0 (accessed on 18 July 2019).

Eastman, J.R., 2016: TerrSet Manual - Geospatial Monitoring and Modeling System. Clark Labs Clark University: Worcester, MA, USA. p. 470.

Foga, S., Scaramuzza, P.L., Guo, S.; Zhu, Z., Dilley, R.D., Beckmann, T., Schmidt, G.L., Dwyer, J.L., Hughes, M.J., Laue, B., 2017: Cloud detection algorithm comparison and validation for operational Landsat data products. Remote Sensing of Environment, 194, 379-390.

Google Developers: Earth Engine Data Catalog. Available online: https://developers.google.com/earth-engine/datasets (accessed on 29 March 2019).

Gorelick, N., Hancher. M., Dixon, M., Ilyushchenko, S., Thau, D., Moore, R., 2017: Google Earth Engine: Planetary-scale geospatial analysis for everyone. Remote. Sens. Environ., 2017(202), 18-27.

Haines-Young, R., 2009: Land use and biodiversity relationships. Land Use Policy, 26, pp. S178-186.

Heydari, S.S., Mountrakis, G., 2018: Effect of classifier selection, reference sample size, reference class distribution and scene heterogeneity in per-pixel classification accuracy using 26 Landsat sites. Remote Sens. Environ., 2018(204), 648-658.

Islam, K., Jashimuddin, M., Nath, B., Nath, T.K., 2018: Land use classification and change detection by using multi-temporal remotely sensed imagery: The case of Chunati wildlife sanctuary, Bangladesh. The Egyptian Journal of Remote Sensing and Space Science, 21(1), pp.37-47.

Kennedy, R.E., Yang, Z., Braaten, J., Copass, C., Antonova, N., Jordan, C., Nelson, P., 2015: Attribution of disturbance change agent from Landsat time-series in support of habitat monitoring in the Puget Sound region, USA. Remote Sens. Environ, 2015(166), 271-285.

Khoi, D.D., Murayama, Y., 2010: Forecasting areas vulnerable to forest conversion in the Tam Dao National Park Region, Vietnam. Remote Sensing, 2(5), 1249-1272.

Lambin, E.F., Turner, B.L., Geist, H.J., Agbola, S.B., Angelsen, A., Bruce, J.W., Coomes, O.T., Dirzo, R., Fischer, G., Folke, C., George, P., Homewood, K., Imbernon, J., Leemans, R., Li, X., Moran, E.F., Mortimore, M., Ramakrishnan, P.S., Richards, J.F., Skanes, H., Steffen, W., Stone, G.D., Svedin, U., Veldkamp, T., Vogel, C., Xu, J., 2001: Our emerging understanding of the causes of land-use and -cover change. Global Environ. Change, $11,261-269$. 
Manandhar, R., Odeh, I.O., Ancev, T., 2009: Improving the Accuracy of Land Use and Land Cover Classification of Landsat Data Using Post-Classification Enhancement. Remote Sensing, l(3), 330-344.

Mustard, J.F., Defries, R.S., Fisher, T., Moran, E.F., 2004: Landuse and land-cover change pathways and impacts in Land Change Science: Observing, Monitoring and Understanding Trajectories of Change on the Earth's Surface. Kluwer Âcademic Publishers, Dordrecht, The Netherlands, 411-429.

Myers, N., Mittermeier, R.A., Mittermeier, C.G., Fonseca, G.A.B., Kent, J. 2000: Biodiversity hotspots for conservation priorities. Nature, 403 (6772), pp. 853-858.

Nguyen, H.T.T., Doan, T.M., Tomppo, E., McRoberts, R. E., 2020: Land Use/Land Cover Mapping Using Multitemporal Sentinel-2 Imagery and Four Classification Methods-A Case Study from Dak Nong, Vietnam. Remote Sensing, 12, 1367.doi:10.3390/rs12091367

Nguyen, H.T.T., Doan, T.M., Volker, R., 2018: Applying random forest classification to map land use/land cover using landsat 8 OLI. Int. Soc. Photogramm. Remote Sens, XLII-3/W4, 363-367.

Nguyen, H.T.T., Ngo, P.T.T., 2018: Land use/land cover change prediction in Dak Nong Province based on remote sensing and Markov Chain Model and Cellular Automata. J. Viet. Env., 9(3), 132-140. DOI: 10.13141/jve.vol9.no3.pp132-140.

Nguyen, H.T.T., 2011: Forestry Remote Sensing: Multi-source data in natural evergreen forest Inventory in the Central Highlands of Vietnam. Lambert Academic Publishing. Germany. 2011, 165p.

Ministry of Agriculture and Rural Development (MARD), 2019: Project on sustainable forest protection, restoration and development in the Central Highlands period of 2016-2030. $M A R D$, Hanoi, Vietnam.

Pettorelli, N., Ryan, S., Mueller, T., Bunnefeld, N., Jedrzejewska, B., Lima, M., Kausrud, K., 2011: The Normalized Difference Vegetation Index (NDVI): unforeseen successes in animal ecology. Climate research, 46, 15-27.

Prakasam, C., 2010: Land Use and Land Cover Detection through Remote Sensing. Approach: A Case Study of Kodaikanal taluk, Tamilnadu. International Journal of Geometics and Geosciences, 1(2), 150- 158.

Rawat, J.S., Kumar, M., 2015: Monitoring land use/cover change using remote sensing and GIS techniques: A case study of Hawalbagh block, district Almora, Uttarakhand, India, Egypt. J. Remote Sensing Space Sci.,18(1), 77-84.

Ruiz-Luna, A., Berlanga-Robles, C.A., 2003: Land use, land cover changes and costal lagoon surface reduction associated with urban growth in northwest Mexico. Landscape ecology, 18(2), 159-171.

Rambo, A. T., Reed, R. R., Cuc, L. T., DiGregorio, M. R, 1995: The challenges of highland development in Vietnam. Honolulu, HI: East-West Center.
Salemink, O., 2018: The Regional Centrality of Vietnam's Central Highlands. In Oxford Research Encyclopedia of Asian History 1-30.

Selcuk, R., Nisanci, R., Uzun, B., Yalcin, A., Inan, H., Yomralioglu, T., 2003: Monitoring land-use changes by GIS and remote sensing techniques: Case study of Trabzon. Proceedings of 2nd FIG Regional Conference, Morocco 1-11.

Sothe, C., Almeida, C.M., Liesenberg, V., Schimalski, M.B. 2017: Evaluating Sentinel-2 and Landsat-8 Data to Map Sucessional Forest Stages in a Subtropical Forest in Southern Brazil. Remote Sen., 2017(9), 838.

Teluguntla, P., Thenkabail, P. S., Oliphant, A., Xiong, J., Gumma, M. K., Congalton, R. G., Kamini Yadav, K., Huete, A. 2018: A 30-m landsat-derived cropland extent product of Australia and China using random forest machine learning algorithm on Google Earth Engine cloud computing platform. ISPRS J. Photogrammetry. Remote Sens., 2018(144), 325-340.

Tewolde, M.G., Cabral, P., 2011: Urban sprawl analysis and modeling in Asmara, Eritrea. Remote Sens., 2011(3), 2148-2165.

Thai, V.T., 1978: Vietnamese forest vegetation. Science and Technique Publishing House Hanoi. Vietnam.

Turner, B.L.II., Meyer, W.B., Skole, D.L., 1994: Global LandUse/Land-Cover Change: Towards an Integrated Study. Ambio, 23(1), 91-95.

Turner, M.G., Ruscher, C.L., 2004: Change in landscape patterns in Georgia, USA. Landscape ecology, 1 (4), pp. 251-421.

Yacouba, D., Guangdao, H., Xingping, W., 2009: Assessment of land use cover changes using NDVI and DEM in Puer and Simao Counties, Yunnan Province, China. World Rural Obs. 2009, 1(2), $1-11$.

World Bank. 2019: Forest Country Note - Vietnam. World Bank, Public Disclosure Authorized, Washington, DC. 